\title{
Zener Relaxation in CuAl Single Crystals Studied by Isothermal Mechanical Spectroscopy
}

\author{
A. Rivière and P. Gadaud
}

Laboratoire de Mécanique et Physique des Matériaux, URA 863 du CNRS, ENSMA, BP. 109, 86960 Futuroscope cedex, France

\begin{abstract}
The Zener relaxation was studied in Cu-Al single crystals. All samples were cut with the same orientation and the $\mathrm{Al}$ concentrations were ranged between 3 and 19 at. \% $\mathrm{Al}$ ( solid solution ).

For low temperature experiments ( $<550^{\circ} \mathrm{K}$ ), perfect Debye peaks are observed in all samples and the relaxation strength is proportional to the concentration square according with the pair reorientation Zener theory.

At higher temperatures and for samples with higher Al concentration only, the internal friction peaks are broader. In the same time, the relaxation strength first increases and then decreases with the measurement temperature according to the short-range ordering LeClaire-Lomer theory with respectively the influence of only neighbouring and more distant atoms.
\end{abstract}

\section{INTRODUCTION}

The Zener relaxation is a type of mechanical relaxation process which has been observed in a variety of substitutional solid solutions, and firstly by Zener [1] in $\alpha$-brass. Generally, the relaxation strength $\Delta$ is dependent on single crystal orientation, increases with solute content $c$ and decreases with measurement temperature [2]. The first theoretical interpretation was provided by Zener [1] who described the relaxation in terms of the reorientation under the influence of the stress of pairs of nearest-neighbour solute atoms. An alternative theory $[3,4]$ suggested that the Zener relaxation is a consequence of stress induced changes in short-range order. $\Delta$ must be proportional to $c^{2}$ in the first case and to $c^{2}(1-c)^{2}$ in the second.

\section{2 . EXPERIMENTAL PROCEDURE}

A series of $\mathrm{Cu}-\mathrm{Al}$ single crystals with compositions of $3.1,5.4,7.3,9.3,11.4,13.7$ and 19 at \% $\mathrm{Al}$ were grown from ultra pure $\mathrm{Cu}$ and $\mathrm{Al}$ by Bridgman technique at the Laboratoire de Métallurgie Physique of the University of Poitiers. The specimens were cut in flat bars ( $50 \mathrm{~mm}$ $\times 6 \mathrm{~mm} \times 1 \mathrm{~mm}$ ) parallel to $\mathrm{a}<111>$ direction and inspected by $\mathrm{X}$ rays experiments. For $\mathrm{Cu}$ $\mathrm{Al}$ alloys, the limit of the solid solution is 20 at. $\% \mathrm{Al}$.

Isothermal internal friction measurements were performed using an inverted torsional pendulum subjected to subresonant forced vibrations [5]. Measurement frequencies were ranged between $10^{-4}$ and $40 \mathrm{~Hz}$ with ten discrete frequencies per decade. Internal friction factor $Q^{-1}$ is directly $\operatorname{tg} \theta$ where $\theta$ is the phase angle between the applied stress and the resulting strain. Relaxation strength $\Delta=\left(M_{U}-M_{R}\right) / M_{R}$ was obtained by measuring directly 
the unrelaxed modulus $M_{U}$ and the relaxed modulus $M_{R}$. The maximum vibration amplitude was $\varepsilon_{M}=5 \times 10^{-6}$

\section{3 . EXPERIMENTAL RESULTS}

\subsection{Temperature dependence of the relaxation strength}

Generally, the relaxation strength was found decreasing with temperature and the theories predict a temperature dependence of the relaxation strength of the type [5]: $\Delta=T_{0} /\left(T-T_{c}\right)$ where $T_{0}$ and $T_{c}$ are constants. Low frequency experiments do not confirm this dependence. So, figure 1 relative to a 19 at.\% specimen shows the Zener peak evolution with the measurement temperature. The peak corresponding to the lowest temperature $(536 \mathrm{~K})$ is exactly a Debye peak. For higher measurement temperature, the peak is wider and higher. Only for measurement above $680 \mathrm{~K}$, the peak height is decreasing, as shown in figure 2 . In this figure, internal friction values measured at $1 \mathrm{~Hz}$ and $16 \mathrm{~Hz}$ in isothermal experiments are plotted against the measurement temperature.

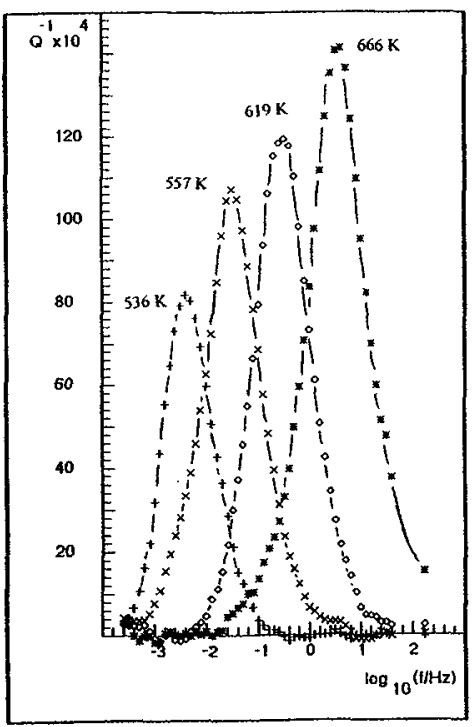

Figure 1 - Cu-19\%Al single crystal Zener relaxation peaks for various measurement temperatures

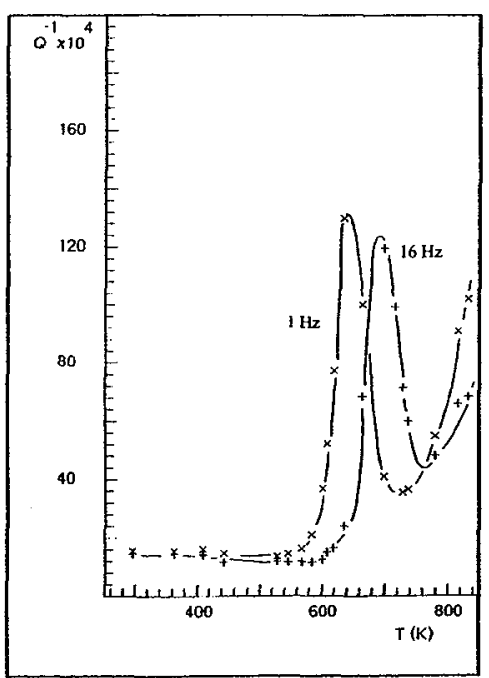

Figure 2 - Cu-19\%Al single crystal Internal friction measured at two frequencies

Such a behaviour was found for each specimen with solute content larger than 7 at.\%.

\subsection{Concentration dependence of the relaxation strength}

In figure 3 , the relaxation strength $\Delta$ is plotted against $\mathrm{c}^{2}$ (fig. 3 a) and $\mathrm{c}^{2}(1-\mathrm{c})^{2}$ (fig. $3 \mathrm{~b}$ ). Evidently, $\Delta$ is proportional to $c^{2}$ only for relaxation peaks obtained at the lowest temperatures (and so at very low frequency) and found identical to Debye peaks. For experiments at higher temperatures, the relaxation peaks were found broader and, in that case, $\Delta$ is not proportional to $\mathrm{c}^{2}$. 
As shown in figure $3 \mathrm{~b}, \Delta$ is never proportional to $c^{2}(1-c)^{2}$ as predicted by the LeClaire-Lomer theory.

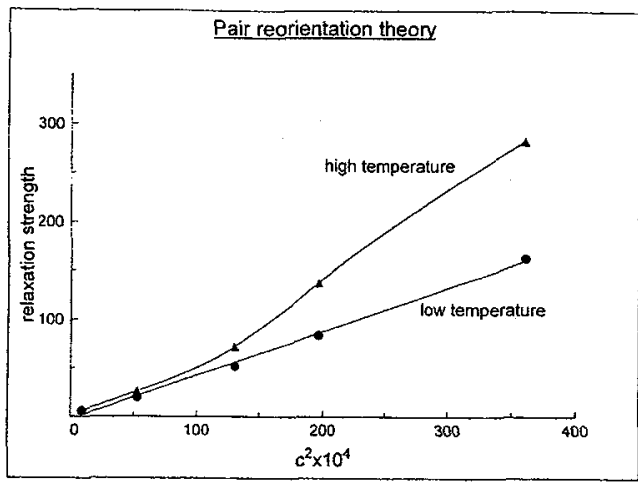

Figure 3 a

Relaxtion strength plotted against $\mathrm{c}^{2}$

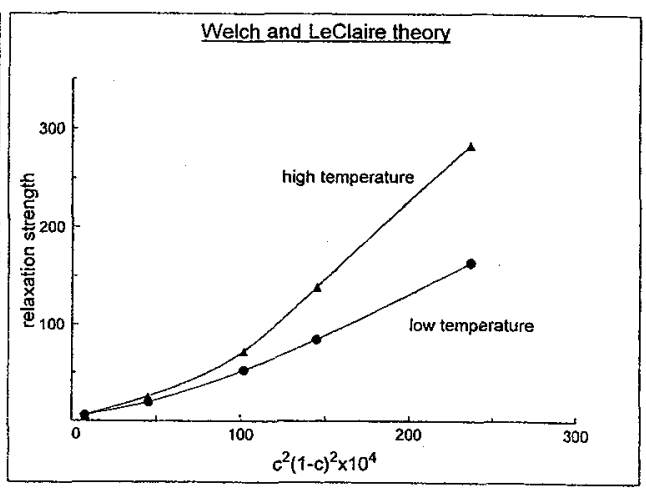

Figure $3 b$

Relaxation strength plotted against $c^{2}(1-c)^{2}$

\section{DISCUSSION AND CONCLUSION}

Table 1 shows the relaxation parameters, apparent activation energy $\left(\mathrm{H}_{\mathrm{app}}\right)$ and limit relaxation time $\left(\tau_{0}\right)$ deduced from our experiments using Arrhenius plots.

Table 1 - Relaxation parameters

\begin{tabular}{|c|c|c|c|c|c|}
\hline \% at. Al & 3 & 7.3 & 11.4 & 13.7 & 19 \\
\hline $\begin{array}{c}\mathrm{H}_{\text {app }} \\
(\mathrm{eV})\end{array}$ & 1.72 & 1.76 & 1.87 & 1.88 & 1.90 \\
\hline$\tau_{0}(\mathrm{~s})$ & $1.6 \times 10^{-14}$ & $1.7 \times 10^{-14}$ & $1.5 \times 10^{-15}$ & $10^{-16}$ & $2 \times 10^{-16}$ \\
\hline
\end{tabular}

The apparent activation energy obtained for low atomic concentration is identical to the value $(1.7 \mathrm{eV})$ obtained from resistivity measurements at low temperature [8] and can correspond to the elementary atomic relaxation mechanism.

For higher solute content, the peak broadening at high temperature induced an increasing of the apparent activation energy and a decreasing of the limit relaxation time.

$\Delta$ is proportional to $c^{2}$ only for measurements at low temperature $\left(T_{M}<550 \mathrm{~K}\right)$ and, in this case, the elementary mechanism is the reorientation of solute atom pairs as predicted by Zener [4].

For specimens with a large solute content and for measurement temperature ranging between $550 \mathrm{~K}$ and $680 \mathrm{~K}$, the relaxation strength increases with measurement temperature. According 
Generally, anisothermal experiments at fixed frequency $(\sim 1 \mathrm{~Hz})$ as described in the literature, correspond to the second case.

\section{References}

[1] J. Woirgard; Il Nuovo Cimento 33B (1976) 424

[2] J. Woirgard, Y. Sarrazin and H. Chaumet; Rev. Sci. Instr. 48 (1977) 1322

[3] J. Woirgard, P. Mazot and A. Rivière; J. de Phys. 42 (1981) C5-1135

[4] C. Zener; Phys. Rev. 71 (1947) 34

[5] A.S. Novick and B.S. Berry; Anelastic Relaxation in Crystalline Solids ( Academic Press, N.Y., 1972)

[6] A.D. Le Claire and W.M. Lomer; Acta Met. 2 (1954) 731

[7] D.O. Welch and A.D. Le Claire; Phil. Mag. 16 (1967) 981

[8] S. Radelaar and J.M.J. Ritzen; Phys. Stat. Sol. 34 (1969) 277

[9] J.M. Cowley; Phys. Rev. 77 (1950) 669; ibid 120 (1960) 1648 ; ibid 138 (1965) 1384 